\title{
An Analysis of the Spatio-temporal Characteristics of Hotels' Network Attention -Taking Xi'an three-star and above hotels as an example
}

\author{
Zhaowen Duan ${ }^{1, a}$, Hanyu Sun ${ }^{1, b}$, Shan Xie ${ }^{1}$,Tingwei Zhang ${ }^{1}$, \\ ${ }^{1}$ School of Tourism \& Research Institute of Human Geography, Xi'an International Studies University, Xi'an 710128, Shaanxi, China;
}

\begin{abstract}
Network attention is the degree of public attention to things on the Internet. With the rapid development of Web 2.0, the network attention of hotels on the tourism network platform has become an important reference for tourists to select an appropriate hotel. Based on the above, taking 371 hotels with three stars and more in Xi'an as the research object and gathering the data of hotels' network attention from www.ctrip.com., we explore the temporal and spatial characteristics of hotels' network attention. The result shows that: (1) From 2016 to 2018, due to the development of hotel online booking business, Consumers' attention to Xi'an three-star and above hotels on www.ctrip.com. has increased significantly; (2) With the Bell and Drum Tower business district as the core, the spatial distribution of network attention of hotels with three stars and above in Xi'an presents the pattern of "large agglomeration and small dispersion"; (3) The network attention of different levels of hotels has obvious differences in spatial agglomeration;
\end{abstract}

\section{Introduction}

In the big data era, the development of China's hotel industry has gradually shifted to an informationized and intelligentized pattern, which in turn leads to changes in the information collection and purchase behavior of tourists. For instance, the amount of network attention and online comments directly affect tourists' decision in the purchase of hotel products. Therefore, the datum has been the crucial information for hotel managers to predict tourist flow and understand tourists' consumption preferences, and also the hot spot in the economic research and practices of hotel industry.

Attention is a way of thinking, learning, and communicating about daily life in the current society, which reflects the public's attention to a certain matter [1]. The network attention of hotels refers to the degree of consumer attention to a hotel on the travel network social platform. It is closely related to the number of reviews published by consumers on this hotel's net platform. The more reviews, the more Internet attention high, and vice versa, the lower the attention of Internet. Presently, scholars, such as Dinis G, have found that network attention has a positive effect on predicting consumer traffic, affecting consumer purchase intention [2-5], and improving consumer satisfaction [6,7]. Currently, mainly using Baidu's index data or web crawler data, Chinese scholars pay more attention to the empirical research of network attention. They focuses on the research of the temporal and spatial distribution characteristics of regional tourism's network attention [8], the spatial-temporal distribution characteristics and influencing factors of network attention of scenic spots [9].

The research on hotel spatial layout is always a hot topic in urban geography, economic geography and human geography. In the 1980s, scholars such as Wall introduced the theory of commercial location and agglomeration economy into the research of hotel spatial layout. For example, commercial and economic hotels are mostly distributed in the fringe and the outer ring of city. With superior location conditions and ecological environment, areas such as Florida, Las Vegas, and Hawaii are hot spots for American hotels to choose their locations $[10,11]$.

In summary, scholars utilize Baidu big data, Google Trends and other network data to analyze the temporal and spatial distribution characteristics of the hotel industry, but often ignore the needs of tourists. Therefore, based on the needs of tourists as the starting point, this study takes three-star and above hotels in Xi'an, China as the research object, discusses the temporal and spatial distribution characteristics of hotels' network attention, with a view to grasping tourists' consumption preferences for hotel products, and providing a useful reference for hotel managers' selection of store location and formulation of marketing strategy, and for the government's management departments' plan for the spatial location planning of the hotel industry.

\section{Data and Methods}

Xi'an, known as Chang'an in ancient times, is one of China's famous tourist destinations. Since the rapid 
development of Xi'an's tourism industry in the early 1980s, hotels, as one of the important service facilities of the tourism industry, have shown a leaping development trend in their growth. As of 2019, there are a total of 868 three-star and above hotels in Xi'an, mainly concentrated in 7 areas in the main urban area of Xi'an, as shown in Figure2.In order to make the research more representative, this paper finally chooses three-star and above hotels of 7 areas mentioned above as the research object.

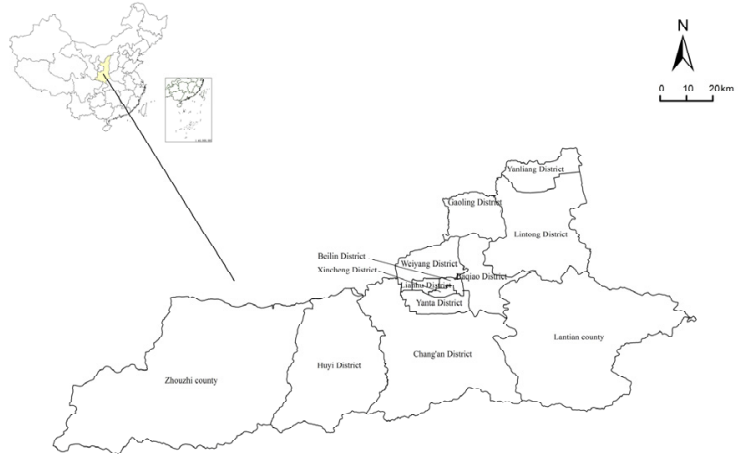

Figure 1. Administrative Division Map of Xi'an

Firstly, this study collects the name, address, detail page link and other data information of three-star hotels and above in Xi'an from Ctrip.com (www.ctrip.com.), which has 600,000 available hotels both at home and abroad. According to the datum, it shows that there is a total of 376 three-star and above hotels which coincide with the research area and comment time (2016-2018). Secondly, the latitude and longitude data of target hotels are obtained in batches by using GPSspg x Geocoding tool, and are loaded into ArcGIS 10.1 after coordinate correction, and then are superimposed with the administrative division and road information of Xi'an. The result shows that 371 hotels are located within and around Xi'an Ring Expressway, and only 5 hotels are in the fringe area of the city. In order to ensure the representativeness of the analyzed data and combine with the "Xi'an Land Use Master Plan (2006-2020) Adjustment and Improvement Plan", these 371 hotels are finally chosen as the research objects of this study. Thirdly, the web crawler technology is used to obtain the star rating, number of guest reviews, date of comment, guest recommendation index, etc. of these 371 hotels. Furthermore, excluding invalid evaluations and repeated evaluations, 456,456 valid comments were finally obtained. Last, the "density analysis" function module of Spatial Analyst tools in the ArcGIS10.1 software is used to measure the distribution law of network attention of the three-star and above hotels in Xi'an. The distribution probability on the surface is inferred by the known point distribution, so the deeper the shadow is, the higher the spatial distribution density is.

\section{Result}

\subsection{The Temporal and Spatial Evolution Characteristics of Hotels' Network Attention}

From Figure2, the network attention of three-star and above hotels in Xi'an is mainly concentrated in the Bell and Drum Tower business district-the center of the main urban area of $\mathrm{Xi}^{\prime}$ an, expanding in the form of a circle and developing into 6 secondary core areas, namely, Fengqing Park, Xiaozhai-Great Wild Goose Pagoda, Train station, Hongmiaopo, the Greenland Convention and Exhibition Center, and the Xi'an International Convention and Exhibition Center. It generally shows the feature of "large agglomeration and small dispersion", which is basically consistent with the actual geographical space layout of Xi'an hotels.

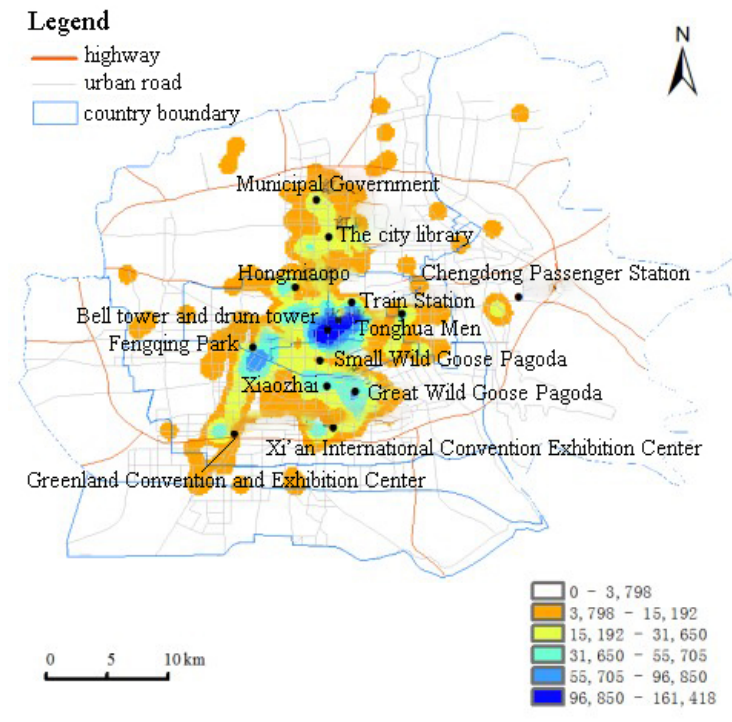

Figure 2. Distribution Kernel Density Map of Three-star Hotels' Network Attention in Xi'an

From Table 1, it is obvious that the number of network attention of three-star and above hotels in Xi'an shows an overall upward trend from 2016 to 2018.

Table 1. Number of network attention of three-star and above hotels in Xi'an

\begin{tabular}{cccc}
\hline $\begin{array}{c}\text { Year/Hotel } \\
\text { level }\end{array}$ & Three-star & Four-star & Five-star \\
\hline 2016 & 29,251 & 39,261 & 22,306 \\
2017 & 65,497 & 81,815 & 45,303 \\
2018 & 58,246 & 78,196 & 36,381 \\
Total & 152,994 & 199,272 & 103,990 \\
\hline
\end{tabular}

In 2016, consumers' network attention to the three-star and above hotels in Xi'an was mainly concentrated in the core area of the Bell and Drum Tower (the central area of the main city of Xi'an). In 2017, the number of consumers' network attention to hotels in Xi'an with three-star and above increased rapidly, and the overall selection of hotel locations was expanded. Besides the Bell and Drum Tower area, hot spots like Xiaozhai-Great Wild Goose Pagoda, Fengqing 
Park, the Greenland Convention and Exhibition Center, the Municipal Library, the Municipal Government, and Hongmiaopo were all added in the customers' selection of hotel locations. In 2018, the number of consumers' network attention to Xi'an three-star and above hotels has declined, resulting in a reduction in the scope of the hotel network's attention space and a weakening of concentration.

\subsection{The Spatial Agglomeration Characteristics of Different Levels of Hotel Network Attention}

Consumers choose different levels of hotels for different reasons, leading to obvious differences in the spatial agglomeration characteristics of Xi'an three-star and above hotels.

(1) Three-star hotel Internet word-of-mouth attention space is mainly concentrated in the Bell and Drum Tower area, which is a single-core space attention type. The Bell and Drum Tower is the center of the old urban area of Xi'an, with convenient transportation and close proximity to well-known tourist attractions such as the Bell Tower, Drum Tower and HUI minority street. Therefore, traffic accessibility and the popularity of nearby tourist attractions are the main factors for tourists to choose three-star hotels in this area.

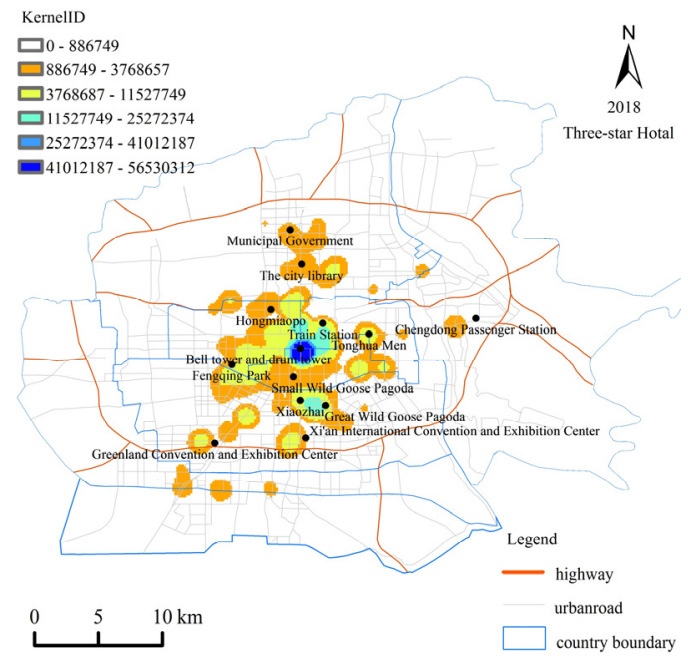

Figure 3. Spatial Agglomeration Characteristics of Three-star Hotels' Network Attention in Xi'an

(2) Four-star hotel Internet word-of-mouth attention space is mainly concentrated in areas such as Bell and Drum Tower and Xiaozhai, which belongs to the dual-core space attention type. In addition to the Bell and Drum Tower, Xiaozhai is on the central axis of Xi'an, which has convenient shopping and is close to famous scenic spots such as the Shaanxi History Museum, Great Wild Goose Pagoda, Ci'en Temple, etc. Therefore, transportation accessibility, shopping convenience, and proximity to tourist attractions are the main factors for tourists to choose hotels in this area.

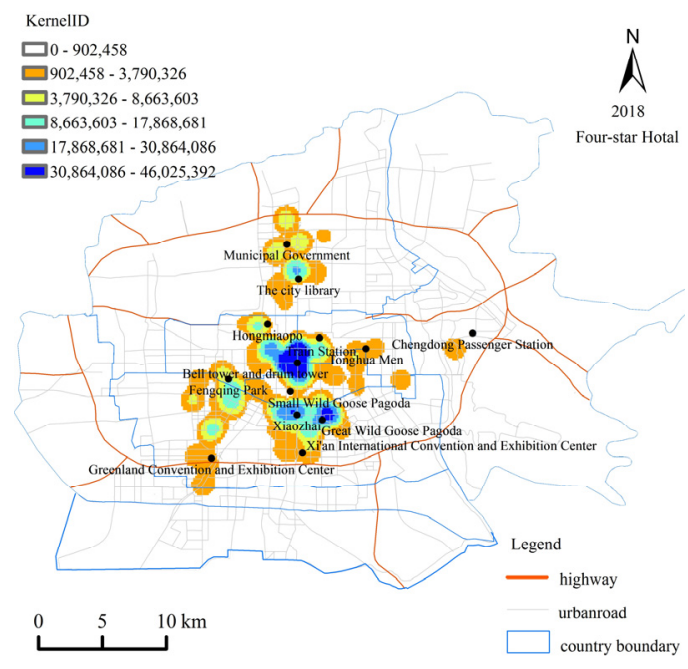

Figure 4. Spatial Agglomeration Characteristics of Four-star Hotels' Network Attention in Xi'an

(3) Five-star hotels' Internet word-of-mouth attention space is concentrated in the Bell and Drum Tower, Big Wild Goose Pagoda, Small Wild Goose Pagoda, Tonghua Gate, Fengqing,Park, Qujiang International Conference\& Exhibition Center and other areas, which belongs to the multi-core space attention type. Hotel hardware facilities, service quality, and surrounding environment have become the main factors for tourists to choose hotels in this area.

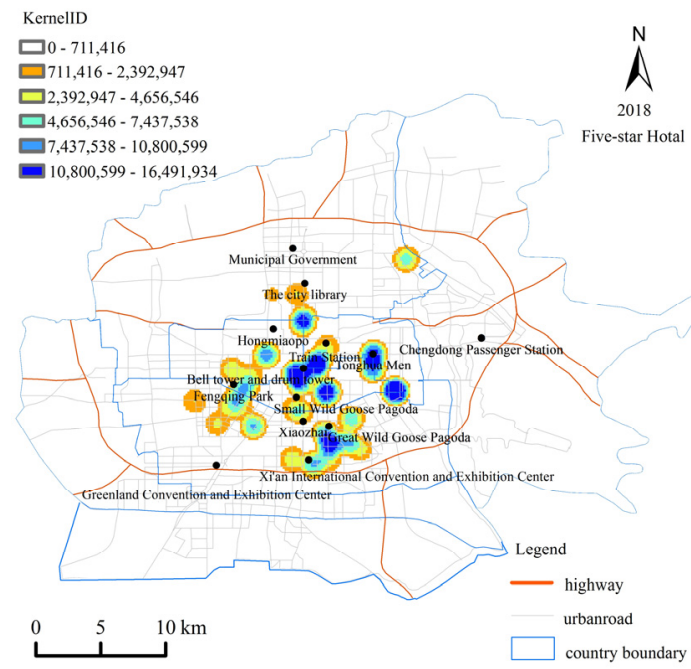

Figure 5. Spatial agglomeration characteristics of five-star hotels' network attention in Xi'an

\subsection{The Influencing Factors of Temporal and Spatial Distribution of Hotels' Network Attention}

(1) The holding of large-scale Events.The First World Western Conference, the First World Science and Technology Conference, and the International Marathon were held in Xi'an in 2017, attracting tourists from all over the world and the number of online booking of hotels increases rapidly. (2) Improvement of Intercity Traffic. The opening of the Xi-Lan High-speed Railway and the Xi'an-Chengdu High-speed Railway in 2017 shortened travel time greatly makes the inter-city travel faster. (3) 
Traffic Convenience. The network attention of three-star and above hotels in Xi'an mainly focuses on these areas, such as Bell and Drum Tower, Fengqing Park, XiaozhaiGreat Wild Goose Pagoda, the Municipal Government, the Municipal Library, Train Station, Hongmiaopo, the Chengdong Passenger Station, and the Xi'an International Convention and Exhibition Center. These places have the developed public transportation network, which improves the accessibility of hotels and reduces the transportation cost of tourists. (4) The Proximity to Tourist Attractions (Spots). As the core area where the network attention of three-star and above hotels in Xi'an is concentrated, the Bell and Drum Tower, the Xiaozhai-Great Wild Goose Pagoda are surrounded by high-level tourist attractions of Xi'an. (5) The Proximity to Large Commercial Shopping Venues. As the core area where the network attention of three-star and above hotels in Xi'an is concentrated, Bell and Drum Tower, and the Xiaozhai-Great Wild Goose Pagoda are close to many important commercial centers, such as Kaiyuan Shopping Plaza, Century Golden Flower Shopping Center, Minsheng Department Store, Xiaozhai SEG International Shopping Plaza.

\section{Conclsion}

Through the statistics and analysis of the number of online reviews of different star hotels in the study area, we found: (1) From 2016 to 2018, due to the popularization of the Internet and the development of hotel online booking business, $\mathrm{Xi}$ 'an three-star and above hotels network attention has increased sharply. (2)With the Bell and Drum Tower business district as the core, the spatial distribution of network attention of hotels with three stars and above in Xi'an presents the pattern of "large agglomeration and small dispersion". Consumers are more inclined to choose hotels in the center of Xi'an's main urban area. (3) There are obvious differences in the spatial characteristics of different star-rated hotels' network attention in Xi'an. Among them, the spatial distribution characteristics of three-star hotels' network attention shows a feature of "single core"; that of the four-star hotels' network attention reveals a feature of "dual-core "; and that of five-star hotels' network attention presents a "multi-core" feature. (4) Many factors will affect consumers' attention and choice of hotels of different levels and locations, including the income of tourists, the holding of large-scale Events, the improvement of intercity traffic, the conditions of hotel facilities, the surrounding environment of the hotel (the convenience of transportation, the proximity of tourist attractions, the convenience of shopping.

\section{Acknowledgments}

We are grateful for the funding support from the Shaanxi Provincial Social Science Foundation Project (No.2020D045).

\section{References}

1. Ratkiewicz J.; Fortunato S.; Flammini A.; et al. Characterizing and modeling the dynamics of online popularity. Physical review letters, 2010, 105(15): 158701.

2. Dinis, G.; Carlos, C.; and Osvaldo, P. The use of Google Trends data as proxy of foreign tourist inflows to Portugal. International Journal of Cultural and Digital Tourism 2016, 3.1, 66-75.

3. Skadberg, Y.X.; Skadberg, A.N.; James R. K. Flow experience and its impact on the effectiveness of a tourism website. Information Technology \& Tourism 2004, 7.3-4: 147-156.

4. Davidson, A.P.; Yu, Y. The Internet and the occidental tourist: An analysis of Taiwan's tourism websites from the perspective of western tourists. Information Technology \& Tourism 2004, 7.2, 91-102.

5. Marchiori, E.; Cantoni, C. The role of prior experience in the perception of a tourism destination in user-generated content. Journal of Destination Marketing \& Management 2015, 4.3, 194-201.

6. Jin, S.V.; Phua, J. Making reservations online: The impact of consumer-written and system-aggregated user-generated content (UGC) in travel booking websites on consumers' behavioral intentions. Journal of travel \& tourism marketing 2016, 33.1, 101-117.

7. Krsak, B.; Kysela, K. The use of social media and Internet data-mining for the tourist industry. Tourism Hospit 2016, 5.197, 2167-0269.

8. Zhang,Y.; He, X. Study on Spatial and Temporal Characteristics of Network Attention of Provincial Tourism Image Slogan Based on Baidu Index. Jiangxi Science 2019, 37(02), 214-220.

9. Sun, X.; Yang, X.; Zhang, F. Spatial Features of Network Attention of Chinese A-grade Show Caves Based on Baidu Index. Journal of Southwest China Normal University (Natural Science Edition) 2018, 43(04), 81-88.

10. Doren; C. S. van; Gustke, L.; D.E. Hawkins; E.L. Shafer. Spatial analysis of the US lodging industry, 1963-1977. Annals of Tourism Research 1982, 9.4, 543-563.

11. Wall, G; Dudycha, D; Hutchinson, J. Point pattern analyses of accomodation in Toronto. Annals of Tourism Research 1985, 12(4), 603-618. 